WellBeing International

WBI Studies Repository

1984

\title{
Animal Boredom: Is a Scientific Study of the Subjective Experiences of Animals Possible?
}

Françoise Wemelsfelder

Instituut voor Theoretische Biologie

Follow this and additional works at: https://www.wellbeingintlstudiesrepository.org/acwp_asie

Part of the Animal Studies Commons, Comparative Psychology Commons, and the Other Animal Sciences Commons

\section{Recommended Citation}

Wemelsfelder, F. (1984). Animal boredom: Is a scientific study of the subjective experiences of animals possible?. In M.W. Fox \& L.D. Mickley (Eds.), Advances in animal welfare science 1984/85 (pp. 115-154). Washington, DC: The Humane Society of the United States.

This material is brought to you for free and open access by WellBeing International. It has been accepted for inclusion by an authorized administrator of the WBI Studies Repository. For more information, please contact wbisr-info@wellbeingintl.org.

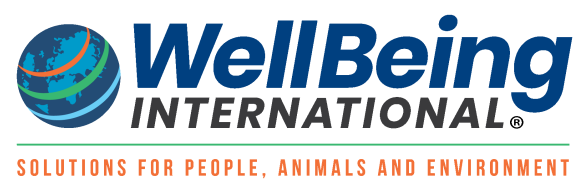




\section{ANIMAL BOREDOM: IS A SCIENTIFIC STUDY OF THE SUBJECTIVE EXPERIENCES OF ANIMALS POSSIBLE?}

\section{Francoise Wemelsfelder}

Instituut voor Theoretische Biologie Groenhovenstraat 5, 2311 BT Leiden Holland

\section{INTRODUCTION}

The study of animal well-being has now become an accepted field of scientific research. Until recently the dominant belief was that subjective experience was inaccessible to the natural sciences, since it could not be experimentally manipulated. It led so-called behaviourists to the denial of any sort of subjective life to animals. This scientific conception of animals is far removed from daily reality, in which people regard and treat animals as sentient beings. Second, the way we as human beings exploit animals for our own sake and profit has caused protest from several groups of people who consider these practices irresponsible and uncaring. Pigs, calves and chickens are "produced" in great quantity in small housing systems for meat consumption; rats and other species are extensively used in experimental laboratories, and all kinds of wild species are kept and bred in zoos. The will to improve the conditions in which these animals live has led to the development of a new field of scientific research: the science of animal welfare.

Marian Dawkins' book Animal Suffering (1980) gives an overview of current theories and problems, and it becomes apparent how difficult it is to find parameters for well-being which are truly adequate, insofar that we can be sure that certain parameters are directly repre- 
sentative of the limits within which animal well-being can exist.

Another, closely related field which has recently started to attract attention is the study of animal awareness or intelligence. D.R. Griffin's The Question of Animal Awareness (1981a) is the first book dealing extensively with the subject. Here too, it becomes clear how hard it is to relate criteria such as communicative ability, or adaptive behaviour to the existence of real understanding and awareness within the animal. What is the final discriminative evidence to distinguish "hardwired" behaviour from intelligent behaviour, or an "instinctive" reaction from a really "felt" reaction? The question whether it is possible to study animal well-being scientifically therefore largely comes down to the question how we can bridge the "communication gap" between man and animal, or how we can become sure that what are usually considered to be indirect parameters are in fact direct.

This question has intrigued me for several years. In discussions with colleagues about the justifiability of vivisection, the argument whether or not animals can feel and suffer played a large role. The fact that something which seemed so obviously true to me was not accepted within a scientific framework and might even be inassessable that way puzzled me. I started to study literature on the phenomenon of pain in animals, since pain is biologically functional, and often overtly expressed; yet it also implies a purely subjective experience within the animal. It seemed to me that pain is a form of subjective feeling which (nevertheless) might be accessible to biological research. I explored this in an ethological research project on pain in piglets after castration without anaesthesia (Wemelsfelder 1982). It appeared that behavioural criteria rather than physiological ones are adequate to study pain, since behaviour represents the self-expression of the animal as an intrinsic whole, including any subjective experience it has. Physiological criteria seem to be more indirectly linked to subjective experience.

However, current scientific methodology regards the reduction of phenomena to lower hierarchical levels as fundamentally desirable, and further there is the great danger of anthropomorphic interpretation of behaviour. Because of these reasons many scientists prefer physiological criteria on principle.

In fact, the importance which is attributed to different parameters or criteria seems to depend on the concept of scientific objectivity itself. Science is not the experience of reality as such; it constructs a representation of reality, and therefore the decision which representations of reality are valid and which are not so valid depends on the choice of a meta-scientific framework.

The aim of this paper is to explore the relationship between different meta-scientific frameworks and the science of animal welfare. 
During the past few years, I have become more and more convinced that the great difficulty science has in studying subjective experience in its objects, might be related to the denial of any role to subjective experience in the observer as an interpretational guide. Can a quality in the world around us be observed, when this same quality is deliberately excluded from the process of observing?

As a practical example for the discussion described above, the phenomenon of animal boredom has been chosen. Boredom implies some sort of awareness, some form of a direct inner experience of selfhood. Because without a sense of selfhood related to the developmental potential of the animal, it would be impossible to "miss" certain things, to be bored. With the phenomenon of boredom one can illustrate the qualitative difference between behavioural and physiological deviations, but is still bored, since it misses the opportunity to perform its specific behaviour. How important behaviour is for an animal is a crucial question in theories on adaptation and stress, and as we shall see, on the existence of animal boredom as well.

Besides the fact that boredom is, theoretically speaking, an appropriate topic for a discussion about the possibility of studying animal welfare scientifically, it is also said to be a major problem for animals in intensive production systems (or bio-industry) and zoos, and in many cases in laboratories as well (van Putten 1982b; Markowitz 1982; Fox 1974). However, many people, farmers and scientists alike, share the view that when animals "are well fed, well watered and the temperature is very comfortable, I do not know what else you could do" (Kirkeide, Secretary of the North Dakota Beef Cattle Improvement Association, in the Grand Forks Herald, Nov. 28, 1982). It seems to be in the interest of the animals, therefore, to discuss whether boredom is a real problem which should be taken seriously, and how we might study and alleviate it if it is a problem and not some erroneous anthropomorphic inference.

Within the framework of the discussion mentioned above the following questions are central in this paper:

1. Can animals be bored, and what are important criteria in the study of boredom?

2. Is there evidence of boredom in intensive animal husbandry?

\section{“OBJECTIVE” SCIENCE AND THE STUDY OF ANIMAL WELFARE}

It has often been said that the study of the subjective is unscientific: inner, personal experiences are private and not accessible to methodological observation. In the science of psychology, verbal com- 
munication between observer and observed bridges most of the gap. In studying animals, however, this way of having access to their inner experience is closed. This dualistic view can be traced back to Descartes' well-known statement that "not only do animals have less reason than humans, they have none at all" (Gilson 1976). The idea that animals are mere material automata, not possessing any of the human "nonmaterial" qualities, has since become quite influential. Yet it is not a logical and necessary conclusion.

To conclude that animals have no inner experience since it is not observable using the scientific method is only justifiable within the framework of the method used for observation. But it is not right to exclude the possibility a priori that the subjective world of animals could be observed and studied with other methods. What is presently accepted as "the scientific method" is not the only absolute guarantee for "objectivity," meaning complete knowledge of an object. Scientific ideas must ultimately be compatible with "common sense," or the common experience of humanity as a whole; with "those presumptions, which, in spite of criticism, we still employ for the regulation of our lives" (Whitehead, cited by Griffin 1977). The natural sciences, excluding inner experience (of animals, and humans as well since behaviorism) from their range of vision, are not compatible with human "common experience." Therefore it might be justifiable to say that current science represents a choice for a certain kind of relationship with the world; a relationship characterized by duality and total detachment between observer and observed, subject and object.

As a consequence of this duality, life has been reduced to material mechanisms; the natural sciences have become reductionistic in principle, with the science of Newtonian (mechanistic) physics at the basis of other, "derived" fields of study (Verhoog 1983).

It is possible, however, to think of a concept of "science" in which the methodological criteria for objectivity are maintained, but in which the ontological starting point is different from the current one. Tranoy (1977) makes this distinction between the two sorts of objectivity, and argues that ontological objectivity, implying a separation between object and subject, is "not universally acceptable..., not even reasonably uncontroversial." Furthermore, it has the serious limitation of excluding oojects that are related to "subject-consciousness," like intentions, norms, feelings, etc. On the other hand, he says methodological objectivity is far more essential for any concept of knowledge. This implies conditions like intersubjectivity and consensus, sincere interest in an object, the absence of arbitrariness, etc. And, as has been said above, a concept of science which is consistent in 
this methodological sense, but is based on a non-dualistic ontological starting point (with emphasis on interconnectedness and interdependence) is very well possible.

The field of animal welfare is pre-eminently one in which different interests are likely to underly the different opinions on the matter. Between economic interests and the interests of the animal, scientific research is supposed to take a neutral position. The role of different scientific concepts in present controversies will now be examined.

Within the study of animal welfare, the subjective experience of the animals of course plays a crucial role. Welfare is in essence a subjective concept, and in order to study welfare, we should study the subjective world of an animal. Almost all natural scientists, however, agree that it is not possible to do experiments to demonstrate (prove) the existence of animal awareness and feeling. Analogy with humans or introspection are considered to be necessary to bridge the gap between outward behaviour and inner feeling, and many researchers are reluctant to do so through fear of anthropomorphism. One even says that "this idle speculation is a burdensome appendage to the real scientific work of observing and accounting for lawfulness in animal behaviour" (Zuriff 1982).

It may well be possible, however, to get access to this very important part of reality. "It is especially in the relationship human-animal (in which the duality object-subject is transcended) that animal consciousness can be best understood... and investigated" (Fox 1983b). Suffering is in principle such an intensely personal phenomenon (Cassel 1982) that it certainly cannot be studied in terms of "lawfulness." It requires willingness of individual observers to interpret data in an empathetic way. After a symposium on animal awareness Wood-Gush (1981) commented: "The general opinion seems to be that it (animal awareness) is very difficult to prove or disprove. The decision one takes is very much dependent on one's sympathy or attitude towards animals."

Those who have an economic interest in animals, accepting their exploitation for our benefit, have a different perspective on and interpretation of the situation than public groups, for instance, whose interest it is to assure the total well-being of the animal. The first group might state: "To exclude animals from fulfilling their role in helping to sustain the human population...is untenable" (American Society of Agricultural Engineers 1981). This point of view is accompanied by the notion that the general public should be informed "of the generally high level of animal care and husbandry exercised on most farms today, whether 'large or small'," since "their perceptions of animals are often unrealistic (oriented to Disney characters, pastoral scenes, and pets)" (ASAE 1981). Furthermore, it is believed that one of the nega- 
tive aspects of "the current controversy on animal welfare" is that it is retarding the movement towards modern "technology which improves production."

Starting from the basic belief that animals exist to serve mankind, the main focus is upon production and efficiency, which at the same time seems to imply a belief that animal welfare in current systems is only marginally, not fundamentally, affected, and that people who think otherwise are sentimental and childish.

People whose primary interest is not to make money for a living by means of animal exploitation, have a totally different opinion; not because they are childish or sentimental, nor are their opinions "unscientific." They speak from the notion of "potential action." Regardless of any facts, we can give animals better housing than they have now, and make them less "unhappy." Ethical responsibility is more fundamental than scientific knowledge, as has been argued before, and therefore to consider nonscientists as "dumb crowds" is a misinterpretation of the fact that "man is a doer, not a knower" (Cave 1982; Debrock 1982). Scientific research in the sense of systematic observation can study different possibilities for reaching a desired goal, and so be a very important tool in making sure that our human ideas are reasonable, and correspond to natural reality.

Many animal-welfare scientists, however, think of the relationship between science and ethics in the opposite way: "The decisions whether or not we exploit animals... and to what extent,....are ethical decisions...that should be made by society at large,... but not without knowing the facts, or scientific evidence, provided by scientific research" (Duncan 1981). This statement can be said to represent the currently accepted view, in which ethical decisions are based on "objective" data. This statement obscures the fact that it is not always easy to discover hard scientific "fact." An interesting example is the phenomenon of adaptation, on which much research is focussed. An animal has to adapt to adverse situations, otherwise it dies. It does so by abnormal behaviour, for example. The question is, does an adapted animal suffer, or does "adapted" imply a calmed-down, relatively content animal? The first answer can be defended from a point of view in which the animal and its environment are seen as a meaningful whole, combined with empathetic observation of behaviour; the second can be defended by saying that behaviour is a stimulus-response mechanism, in which energy outlet is more important than the adequacy of the stimulus. So it seems that there is no "fact" here; the conclusion depends on which point of view one takes. This example will be discussed more elaborately in part I of this paper.

A "vice" that scientists often warn of or complain about is the danger of "anthropomorphic" thinking and reasoning, especially by 
non-scientifically trained people. But respect, involvement, care, and responsibility as integral parts of compassionate stewardship do not necessarily imply sentimental projection. The care is for the animal, and to fulfill its needs, rather than ours. To say that "a pig does not bathe in the mud because it likes it, but because it increases its possibilities for cutaneous evaporation" (Dantzler and Morméde 1979), is a denial of the subjectivity of the animal, and creates the duality between subjectivity and objectivity typical of scientific reductionism. The fear of anthropomorphism might well be a result of fear of taking animals completely seriously as fellow living beings; and for the "burden" of responsibility that would exist if it was accepted that our anthropomorphic notions about animals might be correct.

Biological data relevant to the concept of animal boredom will now be presented and discussed. In doing so, the ontological starting point of nondualism and empathic connectedness as developed in this introduction will be used as a basis. An attitude of empathy, serving as interpretational guideline, might give rise to controversial conclusions in the eyes of those who believe in a dualistic perspective. If it has been argued correctly that the choice of an attitude is primordial to observation, philosophically speaking, and that this choice directs the search for "scientific evidence," then the proposed procedure is justified.

\section{PART I}

\section{ENVIRONMENTAL DEPRIVATION AND THE CONSEQUENCES FOR THE ANIMAL}

The environment provides adequate stimuli to fulfill an animal's needs, and elicits appropriate, species-specific behaviour in an animal. In a diverse, rich environment, an animal has to search for these adequate stimuli (van Putten 1981). In a monotonous, "barren" environment, the animal is not only prohibited from searching for adequate stimuli most of the time, but hardly any adequate stimuli are present. This change in environment has an effect on the behaviour of the animal. What are these effects, and do they matter to an animal? In other words, does a change in quality of the environment affect the quality of the animal's life in a noticeable way for the animal?

\section{DOES BEHAVIOUR MATTTER TO AN ANIMAL?}

Behaviour includes all those processes by which an animal senses the external world and the internal state of its body, and responds to changes which it perceives (Manning 1972). Van den Assem (1973) 
adds that the term behaviour refers only to outwardly observable, mainly motor responses. In the course of time, several explanatory models for behaviour have been presented, which try to reduce behaviour "to a system of hypothetical components" (Manning 1972); components that are linked together in such a way that behaviour can be consistently predicted from certain conditions. “...ultimately we shall hope to explain behaviour in terms of the functioning of the basic units of the nervous system" (Manning 1972).

The question is, in this framework, where and how subjective experience fits into these kinds of models, and in what way an animal experiences its own behaviour.

In relation to the welfare of individual animals in a deprived environment, Hughes (1980) proposes a behavioural model which is an integration of the Lorenzian psychohydraulic model and the mixed-motivation model as developed by Deutsch and Hinde. The first states that behaviour is mainly caused by internal, genetic drives which have to be expressed, even if no adequate stimuli are present; the second model implies that behaviour is mainly triggered by external stimuli in combination with internal, chemical receptors, and, therefore, not performing a certain behaviour does not frustrate the animal. Hughes combines these two into a continuum: some behaviour patterns are mostly internally originated, some largely externally, and many arise through the interaction of rhythmically varying internal motivations and external releasers. In this framework the appearance of distorted or abnormal behaviour in a barren environment is clear evidence of a need for some environmental improvement, so he suggests, since the internal drive apparently is so strong that the absence of adequate releasing stimuli does not prevent an animal from performing abnormal behaviour.

This split into internally and externally regulated behaviour implies that not performing externally regulated behaviour in case of absence of stimuli may not be adverse to an animal. Or, an animal does not miss what it does not know, in other words.

How does an animal experience internally regulated behaviour that becomes distorted for lack of adequate stimuli? Any lack of an adequate environment requires adaptation of the animal to the present conditions. Adaptation is a fundamental property of each animal (Freeman 1975), and "basically all behaviours, including disturbed ones, represent adaptations of an organism to its 'Umwelt"' (Wiepkema 1982).

Proposing a model for adaptive behaviour, Wiepkema (1980) uses the terms "soll-werte" and "ist-werte," meaning, respectively, the way an animal expects its environment to be and the way its environment actually is perceived to be. When there is a difference between 
soll-werte and ist-werte, the animal makes, or tries to make the required behavioural or physiological adjustments in order to solve the conflict. If the gap is too big, however, "abnormal" behaviour is a sign of the difficulty the animal experiences in attempting to control its environment adequately. According to Wiepkema, abnormal adjustments are accompanied by emotions such as fear and general suffering. After a certain time, when the animal has not been able to regain satisfactory control, the physiological parameters revert to apparent normality, and conflict behaviour develops into stereotypic behaviours. These stereotypic behaviours are not necessarily adverse anymore; on the contrary, they might prevent the animal from feeling unhappy, by calming the animal down and suggesting restored controllability (Wiepkema 1982). Discussing Lorenz's psychohydraulic model, Duncan (1981) says that "even if a psychohydraulic model is accepted, it could be argued that as long as the energy finds an outlet (into abnormal behaviour - au) that is not damaging to the hen itself or its flockmates, then welfare will not be adversely affected."

From the models presented above, we could conclude that not performing (potential) behaviour does not matter to an animal; that abnormal behavioural adjustments do matter to animals initially; but that more permanent abnormal behaviour might not be adverse anymore.

This way of looking at an animal and its behaviour, however, is the result of a reductionistic approach: the starting point is a dualistic perspective of animal versus environment, internal versus external. Wanting to reduce behaviour to neural systems (Manning 1972) may imply the view that the subjective experience of an animal is only secondarily, temporarily present.

In a recent article, Baxter (1982/83) gives an analysis of functional behaviour in relation to animal production and welfare, which could illustrate this way of thinking somewhat further.

He states that only those species-specific behaviour patterns which promote biological fitness have survived the pressure of natural selection. By biological fitness is meant reproductive potential, and all factors that contribute to this, such as number and quality of offspring, ability to rear offspring, etc. Subjective well-being therefore must also have some function towards this goal, and "will have been selected on the basis of its representation of biological fitness." Brain programs cause "the animal to change its current state by inducing pleasurable or displeasurable sensations... The study of animal welfare becomes therefore the study of the programs of their brains."

From this perspective he proceeds to say that the consequences of behaviour are crucial for animal productivity, and therefore for their welfare, rather than the behaviour itself: "allowing an animal to per- 
form behaviour is one way of accommodating requirements, and is not the requirement itself.... This opens the possibility of accommodating animal requirements entirely by environmental manipulation and without the animal performing behaviour." Ethology in this framework becomes an attempt at functional interpretation of behaviour, rather than a study of behavioural requirements in their own rights.

In short, subjective experience, and behaviour are said to be secondary means towards the goal of (re)production. The motor which moves the different parts of the mechanism is the central nervous system. And, as Ingram (1981) comments: "if an animal survives so that its DNA gets into the next generation, it has been a success."

These perspectives on behaviour do not regard animals as individual, qualitative, sensitive beings, but as mechanisms which find their reason for existence in quantitative production.

From a nondualistic perspective in which qualitative relationships are crucial for the animal's well-being it does matter to an animal when it does not have the chance to perform the behaviour which is part of a species-specific range of behavioural possibilities. The behavioural potential of an animal represents the quality of the animal-environment relationship. Rather than regarding behaviour as a means towards reproduction (in other words quality serving quantity), a nondualistic perspective regards reproduction as a means towards individual life and behaviour (quantity serving quality). Subjective experience is intrinsically present in all activity and together with behavioural expression represents the meaningfulness, the telos, of animal life.

In this way, distorted abnormal behaviour is an indication of an affliction upon the quality of the animal's life. What follows is a further discussion of abnormal behaviour, its forms of appearance and function.

The types of abnormal behaviour which occur mostly in barren, deprived environments are stereotypic behaviour, redirected behaviour, vacuum behaviour (van Putten 1981) and over-reactiveness to sudden disturbances (Metz and Oosterlee 1980; Stolba and Wood-Gush 1980). Stereotypic behaviour mainly consists of the constant, compulsory repetition of certain motor patterns, resulting from a lack of general stimulation, or a lack of exercise. Redirected behaviour implies the fulfillment of behavioural needs on inadequate stimuli, and is often harmful or damaging to the animals, since parts of the body of mates often form the substitute for the original inanimate stimulus. Vacuum activity occurs when no appropriate stimulus is present at all, and the behaviour is performed "in the air," e.g., the air-chewing of sows in confinement. Over-reactiveness can be seen in, e.g., the alarm-reac- 
tion after sudden disturbances or the response to novel stimuli in a bare environment.

"In severely impoverished environments, arousal is generally increased,...due to an unsatisfied, strong motivation for certain activities" (Stolba and Wood-Gush 1980). By performing abnormal behaviour, the animal often "creates" its own stimulation, thereby reducing the increased arousal (Fox 1971; Vestergaard, 1981).

Again, as has been mentioned before, one can ask the question whether "abnormal behaviour actually is an advantage for the animal, since it reduces arousal" (Moss 1981b) but the answer must be "no" if we consider it from the perspective of the larger whole of an animal's nature and potentials.

A deprived animal, when placed in a rich environment, will overreact and indulge in a certain behaviour pattern (Wiepkema 1980). Even when an animal has been performing a certain behaviour on nonadequate objects e.g. bar-biting of sows, or "in the air" (vacuum-activities) it will immediately and strongly respond to adequate stimuli when these are given after the performance of displacement behaviour. This clearly indicates that an animal does discriminate between adequate and nonadequate stimuli, and that real satisfaction is not derived from adapted behaviour, otherwise the animal would not react so vigorously to adequate stimuli (Sambraus 1982; van Putten 1981; Stolba and Wood-Gush 1980). Sambraus mentions feeding and sexual behaviour as examples; sleep behaviour is furthermore added by Wiepkema. Stolba and Wood-Gush (1980) showed that the more bare the environment was, the stronger did piglets show the urge to explore new objects.

The fact that an animal has a telos, or intrinsic nature, implies that the fulfillment of its potential capacities matters fundamentally to it; every animal has a strong urge to be active and alert.

This is most clearly shown by some experiments which indicated that animals prefer to work for food, even if they do not have to. Markowitz (1982) describes how ostriches, who had learned to press key in order to obtain some peanuts as a reward, preferred to work in this way for their food instead of having it free. When a keeper accidentally dumped a whole bag of peanuts in their cage, they went over to the heap, sampled a few peanuts, and went back to their key to "earn". their peanuts. Wood-Gush (1973) mentions this phenomenon for chickens.

As others have repeatedly found, animals will typically work for food even when the same food is available free. This phenomenon "has been disquieting for some traditional learning theorists. After all, this illustrates how...superficial some of our explanations of animal behaviour are.... We are emphatically confronted with the proposition 
that also animals like to do things, to see things change because of their efforts, to enjoy the pride of gathering their own food or drink, and to have some control over their lives. This is what behavioural enrichment is all about" (Markowitz 1982).

When an animal can fulfill its telos, and express its natural behaviour freely, it is generally recognized as being a contented or "happy" animal. Subjective experience, fulfillment and quality are inseparable aspects that come together in the behaviour of an animal.

What are the basic behavioural needs of animals, indicated by the concept of telos? Of course, this is basically different for each species, but attempts have been made to generalize some basic needs into behavioural categories.

\section{BEHAVIOURAL NEEDS OF ANIMALS}

In an attempt to determine behavioural needs of domestic animals, as well as those of laboratory animals, the question whether or not these animals are fundamentally different from their wild ancestors is a crucial one (Duncan 1981).

On a population level, adaptation is the result of changing gene frequencies (Beilharz 1982), caused by environmental pressures; a process called "natural selection." In the case of domestic species, another important factor has been selective breeding by man for certain desirable traits, such as docility and productivity.

It can be stated that those animals that have adapted their genotype continually to the demands created by man are very different from their wild ancestors (Beilharz 1982; Hughes 1980; Duncan 1981). An example of this might be the elimination of incubation and broody behaviour in the domestic chicken (Wood-Gush 1973; Craig 1982), although Brantas (1980) describes the frustration that occurs in hens that do not have a nest in which to lay their eggs. In the discussion after Brantas' presentation, it was remarked that the hens might have been frustrated because they had experienced laying in nests before. Whether behaviour is learned or not, it remains a fact that the animals respond adequately to stimuli which used to be a part of their ancestors' natural habitat.

Wood-Gush and Stolba (1982) report that pigs, kept in a "pigpark" with "a variety of environmental features, and a diversified social structure," show behaviour "that closely resembles behaviour described for the European wild boar." Boice (1981) in a review article of studies on captivity and feralization, states that "captivity and domestication do not necessarily produce behavioural degeneracies." As an example he mentions an experiment that showed that for albino 
Norway rats, placed in an outdoor pen, "hundreds of generations of life in captivity have not altered the burrowing abilities of Norway rats." Systematic studies of the effects of feralization have shown that for a large number of species, animals placed in an outdoor pen resume their wild ways. Therefore, in order to understand the function of behavioural traits in domestic animals, and their importance for the animal, scientists need to study the wild ancestors of our domestic species thoroughly (Hartsock and Strickland, personal communication, 1982). Besides, domestication does not refer to today's intensive production systems. It is very unlikely that animals who always have been kept in extensive or semi-extensive conditions, have been able to adapt to the rapid changes of the past 20 years (Wood-Gush, as reported by Buchenauer, 1981).

So, on a population level, it is very likely that much of the potential for the full range of behaviour of wild ancestors is still present genetically, despite some selective, mostly physical changes. Baxter $(1982 / 83)$ remarks that selective pressure on agricultural animals might even have strengthened original traits aimed at biological fitness rather than diminishing them. This would include traits like nesting behaviour. For zoo animals hardly any intentional selection takes place, and therefore their behavioural needs will resemble the needs of their wild conspecifics very much.

The following behavioural categories are considered to correspond with the most basic needs of animals:

Eating and drinking behaviour, especially search behaviour, is agreed upon by several authors to be crucially important (Fraser 1980; Sambraus 1981). A long list of abnormal and stereotypical behaviour related to this exists for many farm animal species (Sambraus 1981), indicating that the animal's internal drive to perform this behaviour is strong. He reports that when, for example, chickens are given their food in straw so that they have to search for it, they show a decreasing amount of abnormal feather-pecking. In zoos too, devices that are invented to make an animal work for his food rather than being fed at regular times, have caused drastic changes in formerly apathetic, inactive animals (Markowitz 1982).

Closely related to this are explorative behaviour and locomotion, considered almost as important as ingestive behaviour (Fraser 1980; Sambraus 1981). Stereotypic weaving of, e.g., polar bears and horses is interpreted to be evidence of lack of exercise and space to move, and disappears when more space is provided (Meijer-Holzapfel 1968; Fraser 1968). Daschbach et al. (1982/83) consider the importance of enough space for the locomotory behaviour of encaged monkeys (the slow lori, Nycticebus concang, in case), since too little space, especially if less than the so-called "flight-distance," can cause increased ag- 
gression, physical damage and resulting stress. (Flight distance refers to the linear distance between an animal and an animal of another species which is tolerated without fleeing.)

Exploratory behaviour is a strong drive, generally present in most animals, which serves to increase familiarity with the environment (Baxter 1982/83). Even when the possibility for locomotion is present, many abnormal adjustments appear when there is an absence of objects which are explorable. In pigs, for example, a well-known vice called tailbiting (which is a redirected activity) is considered to be directly related to a lack of exploratory possibilities, and causes significant economic losses (Sambraus 1981; Murphy 1978; Wiepkema 1982). Ekesbo, as reported by Duncan (1981) has shown that the incidence of trampled teats and clinical mastitis is higher when dairy cows are housed in small stalls without bedding. And these are only a few of the numerous examples of the damage that is done to animals physically and mentally by deprivation of adequate stimuli and the restriction of space.

The possibility of relating to the environment in a normal, healthy way is strongly represented by play behaviour. Especially for young animals, playing is of essential importance for their normal development, since it provides the possibility for a dialogue between the animal and its environment (Buchenauer 1981). Young animals develop their own ability for action through the interplay with the environment (Buchenauer 1981; Wood-Gush 1973); they acquire independence from the mother, learn to interact with peers (Jensen and Bobbit, cited by Fox, 1974) and develop motor control (Fraser 1980). By playing, the young animal gradually learns to be less dependent on its mother, and to control its environment on its own. "The entire basis for intelligence, for the acquisition of information, and for learning itself hinges upon early playful exploratory behaviour" (Fox 1974). Fraser (1980) further mentions comfort activities like grooming and nest-building, both of which are recognized as being of primary importance for the domestic chicken (Wood-Gush 1973; Hughes 1980), and the pig (Sambraus 1981); as well as sleeping and social behaviour.

As Fraser (1980) concludes, these needs seem formidable. But rather than being discouraged by the long list of behavioural needs, it might be important in this framework to summarize the discussion above by saying that most present animal-confinement systems, be it zoos, laboratories or intensive-production systems, have a great need for more "general stimulation," whatever stimuli this might imply.

Too little general stimulation, and a (fundamental) lack of the possibility for self-expression, deprive human beings and animals of a sense of fulfillment and satisfaction. In other words, a qualitatively poor environment leads to deprived, bored animals as a result (Murphy 1978). 


\section{BOREDOM AS A RESULT OF ENVIRONMENTAL DEPRIVATION}

Considering environmental deprivation, it is meaningful to make a distinction between social environment and physical environment (Duncan 1981).

Clearly, for social animals the social environment is of crucial importance. All agricultural domestic animals are social species, which means that they normally live in groups with an organized social structure (Duncan 1981). Most laboratory animals such as mice, rats, dogs and monkeys are social animals, too. Duncan mentions and discusses several possible kinds of social deprivation: prevention of the formation of a parent-offspring bond, early weaning, the keeping of animals in single-age or single-sex groups, and isolation. Some effects of social deprivation are a higher mortality, increased aggression, displacement behaviour (e.g., calves, lambs and piglets who are weaned early suck each other, or perform vacuum-sucking behaviour); distorted behaviour (such as isolated cockerels chasing their own tails), physiological effects like a high incidence of arteriosclerosis (Duncan 1981) and "learned" helplessness (Fox 1983a).

However, since a more common problem in farms is overcrowding, rather than social deprivation (Murphy 1978), it is mainly the impoverished physical environment that makes people question animalkeeping systems like zoos, laboratories and intensive production units. The so-called "barren environment" is referred to by many authors in their discussion of animal welfare (Hughes 1980; van Putten 1982b; Wood-Gush 1973; Duncan 1981; Buchenauer 1981; Brantas 1975). "What could be more unhealthy than an unresponsive environment?" Markowitz (1982) asks in his book about behavioural enrichment in zoos. He reports on the beneficial effect that environmental enrichment had on the performance of species-specific behaviour of polar bears: reduced stereotypic activity, greatly improved physical health (not in the least because they stopped begging for junk-food from zoo visitors), and reduced aggressive behaviour of males towards newborns. All too familiar is the stereotypic behaviour of caged zoo animals, from canaries, foxes, coyotes, bears, etc., to great apes. The latter are also known to eat their own vomit and faeces (Fox 1971).

For laboratory animals, nervous anorexia, coprophagia (eating of faeces), polyphagia and polydipsia (eating and drinking too much), as well as asocial, stereotypic and aggressive behaviour can be results of social and environmental deprivation (Fox 1974).

A related area of concern is the lack of general stimulation for dogs and cats in shelters. Isolation and understimulation can cause hyster- 
ical, high-pitched barking, abnormal behaviour such as a dog chasing his own tail, and a general appearance of nonalertness: dull coats and eyes. This can be improved by providing toys such as sticks, balls and blankets. But for animals used to being so close to human beings, the most important need they have is human contact. All other needs such as exercise, play etc., are dependent on the presence or absence of human attention. To have a relationship with human beings has become the most important aspect of the nature of a dog; far more so than for a cat (Wright, personal communication, 1982). However, even for piglets the presence of two human caretakers can make a difference of 5 kilograms growth per pig per 6 weeks! (Hammer 1980).

In Part II, the problem of environmental deprivation in agricultural animals will be discussed more elaborately. Many scientists use the term "boredom" with or without quotes, in talking about the subjective experience of animals in a deprived environment (Wood-Gush 1973, 1981; Murphy 1978; Duncan 1981; Griffin 1981b; Humphrey 1981; Kiley-Worthington 1981; Vestergaard 1981). This phenomenon can be explained biologically in terms of "a motivational state which drives the animal to increase its overall sensory input" (Murphy 1978; see also Griffin 1981b).

But before it can be accepted that animals can be bored, there are some questions that have to be considered first, according to several authors. Can one apply a concept like boredom to "an animal as primitive as a fowl, particularly if its behaviour is largely governed by releasers?" (Wood-Gush 1973). "Does it matter to an animal whether the necessary stimulation comes from the environment directly or whether from themselves by performing a stereotypy in a non-stimulating environment?' (Murphy 1978). Is boredom a term which applies only to humans, as Duncan (1981) says, and which does not refer to an equivalent mental experience in animals (Murphy 1978; Humphrey 1981)?

Although several authors raise these questions, most of them go no further than to offer a few speculatory lines. Griffin (1981b) suggests that "since laboratory rodents will run several kilometers every night in an exercise wheel, while wild conspecifics never seem to go more than $100 \mathrm{~m}$. from their nest, the laboratory animal might be bored." Some people say, however, that despite all the evidence that animals do prefer to respond to external stimuli when these are present, this still does not answer the question whether animals miss what they do not know (Ewbank 1981), or whether they actually suffer in the absence of stimuli (Wood-Gush 1973). Because intuitively, that seems to be what boredom implies: missing stimuli that should be there but are not.

The presence of stereotypies in zoos and laboratory animals, and 
all domestic species, however, strongly suggests that an animal does miss general stimulation, otherwise it would not develop these highly repetitive, unnatural behaviour patterns to stimulate itself, nor would it engage in all kinds of harmful and physically injurious displacement activities. This is where the second question comes in: does it matter to the animal how it satisfies its need for stimulation; do animals have a sense of "quality of life" as suggested by Murphy (1978).

From a reductionist point of view, there might be no decisive answer to this question. Subjective experience is considered to be a secondarily derived factor in reductionistic explanatory models. A fundamental way of taking subjective experience seriously, as a central feature of life, requires a shift of observational perspective (or "gestalt-shift"').

From such a perspective we see behaviour not solely as a means towards a reproductive end. Baxter's (1982/83) statement that behaviour is "one way of accommodating requirements, and not the requirement itself" is direct evidence of an approach which reduces the animal to a functional mechanism. In this approach boredom could not exist as long as the desired production were guaranteed. A shift from quantity to quality does imply that behaviour is seen as the requirement itself.

In this framework an animal can be said to be bored when it has to adapt to its environment in an abnormal way, indicative of understimulation, in order to maintain its sense of selfhood. The continuity between man and animal, and the evidence for feeling and awareness in animals (see Section I, The Question of Animal Awareness, in this volume) imply that boredom is a direct subjective experience of an animal.

It is not always easy to distinguish "boredom" from "frustration." Boredom can give rise to frustration, e.g. when a sow tries to break away from its ties to build a nest, or when aggression in battery cage hens increases as a result of deprivation of nesting boxes for laying-behaviour. An aggressive bird can hardly be called a bored one, yet it is important to realize the close link between the two phenomena. Boredom could be regarded as a qualitative description of the psychological state that gives rise to general frustration.

An advanced form of boredom is the phenomenon of helplessness, elaborately described by Seligman (1975) for human beings, and by Fox (1983a) for animals. After a prolonged time of lack of control and predictability over the environment, animals "give up" trying to express themselves and become apathetic. Van Putten describes this for tethered sows: the sow sits, lets its head hang down and has its eyes nearly closed. This has been referred to as "mourning" behaviour (van Putten 1982b; see also Fox 1983a). In laboratory animals it is often present as a result of experiments, and the animal's inability to control 
its life (Fox 1982). Helplessness is characterized by the general refusal to respond, even to novel stimuli, or damage being done to its own body; these traits distinguish helplessness clearly from habituation (Fox 1983a). Further effects are decreased learning ability, immunosuppression, loss of weight and appetite, norepinephrine depletion and increased cholinergic activity (Fox 1983a).

Helplessness is the pathological mental state arising from the animal's conviction that, whatever it does, it cannot have any real control over its environment. It believes (or has learned) that responding is useless, since there will be no reinforcement to the response (Seligman 1975). If lack of natural stimuli can produce such a pathological state, equivalent to mental illness and depression in humans, then surely it matters to an animal that it be provided with an environment that gives it the chance to be a mentally and physically healthy animal, rather than a bored or helpless one.

\section{THE SCIENTIFIC ACCESSIBILITY OF BOREDOM}

Although there have been no attempts to conduct systematic research about the phenomenon of boredom, methods to do so might be indicated.

Discussing possible parameters for the observation of boredom, it is helpful to realize that boredom is a relative as well as an absolute phenomenon. It is relative in the sense that animals perform a greater variety of behaviour patterns in a more stimulating environment, and therefore any environment can be said to be boring in comparison to a richer environment. A rich environment can give us an idea of the behavioural potential of different animal species, and may serve in this way as a frame of reference for the evaluation of understimulating environments, and for the interpretation of the abnormal behaviour occurring in them. Boredom is an absolute phenomenon so far as lack of stimulation becomes apparent in abnormal behaviour patterns.

For adequate observations of an environment that is suspected to be boring, the following conditions seem to be essential:

1. A thorough knowledge of the species-specific behaviour and its development in a rich, stimulating environment, whether it be wild or domestic.

2. Observations of animal behaviour over long periods of time, preferably 24 hours, or 12 hours a day. The occurrence of different behaviour patterns can be evaluated best in this way, since boredom is a concept related to time.

3. The presence of the observer must be concealed, or it must be certain that this does not influence the behaviour of the animals 
in any way. In relation to boredom this is especially important since human presence is itself a stimulation which might temporarily obscure evidence of boredom.

The following criteria for boredom are proposed:

1. Stereotypic movements.

2. Redirected activity which occurs systematically towards inadequate stimuli.

3. Vacuum behaviour.

4. General apathy and immobility over longer periods, accompanied by an inalert expression in the eyes, if possible to observe. This includes longer periods of sitting and standing. The first three behaviours are evidence of the fact that an animal is still trying to cope with a lack of stimulation. The fourth, advanced state of boredom indicates the impossibility for the animal to express itself; it has more or less given up trying to adapt to the situation.

The presence of any one of these behaviours is a direct indication of the fact that the environment is inadequate for the behavioural needs of an animal. It is generally agreed that understimulation is the main cause for the behaviour patterns which are proposed as indicators of boredom. Everyone who spends a short time in a particular intensive production system can observe the presence of stereotypic behaviour, vacuum activities or redirected activities such as forms of cannibalism. These are all qualitative indicators that the environment is a boring one to which the animals have to adapt in an abnormal way. As was said before, larger periods of observation are desirable for a more detailed scientific description of the situation. However, it is questionable whether at present this is really necessary. Much is known already about the occurrence of abnormal behaviour in farm animals, enough to indicate the actual need for environmental enrichment in intensive systems.

Accepting that boredom is an adverse state, it can be regarded as a form of stress for the animal. Stress is a phenomenon that has mainly been studied in terms of internal processes. That is, what are the effects of external stressors on homeostasis, which is the regulation of the internal environment to maintain an internal equilibrium. In order to gain insight into the way boredom acts as a stressor on an animal, a general theoretical framework of stress will be discussed. Central questions in the development of such a framework appear to be "what is normal?" and "is the maintenance of homeostasis a good criterion for the absence of stress?" Secondly, "what are the best parameters for abnormal, stressful states?" As will become clear, the last question concentrates on the usefulness of behavioural versus physiological parameters. 


\section{BOREDOM AS A STRESSOR}

Within the difficult and vague field of stress research, the concept of a General Adaptation Syndrome (GAS), as developed by Hans Selye was a major breakthrough (Moss 1981a; Friend 1980; Ewbank 1973). One of the important aspects of his work was his distinction between "stressors" and "stress response," the first referring to adverse or noxious stimuli, the latter to the mechanisms by which an animal resists the effects of adverse stimuli (Ewbank 1973; Moss 1981a). He defined stress as a specific syndrome in a biological system, consisting of all nonspecific responses to a stressor.

Although Selye's work is still very influential, Fraser, Ritchie and Fraser (1975) have pointed out that the concept might be too simple. First, specific stressors may not only generate nonspecific responses but very specific ones as well (Siegel 1980; Dantzer \& Morméde 1981), depending on the nature of the stressor. Second, while overstimulation might cause a certain (general) reaction, it has become clear that animals can be understimulated as well, which might also cause a physiological reaction. In terms of the response of the animal, one could speak of "understress," "stress" and "overstress" in this context, thereby indicating that "stress" in itself is not adverse, but that only extreme effects are deleterious to the animal (Ewbank 1973; Freeman 1978).

This immediately raises the question whether it is possible to determine a "normal" baseline of stress in order to see which stressors are "beneficial" (building up biological fitness) and which are adverse (Fraser, Ritchie and Fraser 1975; Freeman 1976; Perry 1973). A study on the variance in corticosteroid levels during egg-laying in hens (Beuving 1980) showed also, however, that changes in normal behaviour correspond to variations in hormone concentration. This makes it very hard to interpret any response of the adrenal glands as adverse or normal. In fact, an animal is never in a static state, but always acting and reacting to external and internal stimuli, in order to maintain a state of internal, physiological homeostasis (Ewbank 1973).

This state of homeostasis is widely regarded as the "normal" state. "The psychological setpoint at which there is no effect on welfare, represents the homeostatic setpoint" (Baxter 1982/83). Behaviour, in this context, is regarded as the means by which an animal maintains homeostasis and adapts to the environment (Wiepkema 1982; Buré 1981a).

If the pressure of certain stimuli rises, however, and it becomes harder for an animal to maintain a homeostatic equilibrium, the internal stress-response leads to a stage which is referred to as "the resistance stage," a concept introduced by Selye (Fraser, Ritchie and 
Fraser 1975). If the stressors in the environment are too severe, or are present too long, the stress-response proceeds into the so-called "exhaustion stage" which will result in death, if nothing is done (Freeman 1978; McBride 1979).

It is now widely believed that adaptation to a stressful situation (a stressor) eliminates that event from being a stressor (Friend 1980 referring to Mobey), which implies that only when an animal's physiological state is in the stage of exhaustion, can it truly be called stressed in its adverse meaning (McBride 1979; Perry 1973). A very practical aspect of accepting this concept of stress is that in domestic situations, most animals are slaughtered before they could reach the exhaustion stage, and therefore it is hard to determine whether some stimuli should be classified as highly stressful or not (McBride 1979; Freeman 1975). Furthermore, the psychophysiological costs of adaptation, which may lower the animal's ability to cope with additional stressors, need to be considered when it is believed that an animal has actually adapted to a given set of stressors.

In the model of stress outlined above, "normal" as a standard for an acceptable level of stress-response can be replaced by "adaptèd" (Bessei 1980), and is represented by a homeostatic state.

Several authors agree upon the fact that stress primarily must be determined by means of physiological parameters, since homeostasis is a physiological phenomenon (Freeman 1976; McBride 1979; Friend 1980). "...It is quite clear that evidence will come from physiologists and not ethologists. It is they who must face the problems of measurement and definition" (McBride 1979). If, after the initial acute physiological response to adverse stimuli, physiological changes remain, it might well mean that the situation has become too severe and that the animal cannot adapt through its behaviour. This is the worst kind of stress, leading to death. If the initial physiological response disappears after a while because of behavioural adaptation, then the developed homeostatic state is not recognized as stressful according to the framework presented above. In other words, a decrease of physiological deviation is directly correlated to a decrease of stress. Abnormal behaviour has been reported to cause a decrease in corticosteroid reaction (Dantzer 1981; Buré 1981b; Dantzer and Morméde 1981), and therefore might be regarded not as a sign of stress, but as a means towards decreasing stress (Wiepkema 1982; Dantzer and Morméde 1981).

It must be questioned whether it is appropriate to consider homeostasis as a standard of what is "normal" in this respect, since the price that animals have to pay in order to be able to adapt is completely left out of account. And the distortion of the intrinsic nature of an animal, caused by the performance of abnormal behaviour, is a high price indeed. 
As Fraser, Ritchie and Fraser (1975) pointed out, from a veterinarian, animal-centered point of view, the quality of the process of coping is as important as the final result. Referring to "the perennial disagreement" about the question whether behavioural disruptions could by themselves be regarded as symptoms of stress, without physiological confirmation, they state that this is justified, since "a system of husbandry is clearly in need of improvement if adverse consequences are prevented only by gross changes in either behaviour or physiology" (emphasis added).

To understand the role behavioural and physiological factors play it is important not just to understand the relationship between behaviour and physiology, but to understand first of all the relationship of each of them with the nature, or beingness of the animal.

First of all, it is possible that there are as yet unknown physiological indicators, other than adrenocortical hormones, which do correlate with emotional behaviour. Heart-rate, cardiac output or skinresistence (Baldwin and Stephens 1971) or other neurohormonal systems (Dantzer and Morméde 1981) have been mentioned as possibilities. In this case behaviour and physiology would both refer to the same state of being of the animal. The suggestion that there also might be a fundamental difference regarding their function for the animal is elucidated by Seligman (1975), in his book Helplessness. Since helplessness is an advanced form of boredom, as was described earlier, Seligman's remarks apply very well to the study of boredom. After discussing several experiments, he concludes that the neurotransmitter norepinephrine (NE) level appears to be a very important physiological parameter for a feeling of control over the environment in humans and animals. However, he goes on, "NE-depletion alone cannot account for many of the facts that the cognitive theory predicts, since NE-depletion seems to be neither necessary nor sufficient to produce learned helplessness...The difference between escapability and inescapability is not physical; it is information that can only be processed cognitively." The way in which this information is processed in a particular situation depends on the behavioural possibilities the animal has for controlling its environment (e.g. to escape or not). Cognition and emotion are inseparable (Seligman 1975) and so cognition, emotion and behavioural possibilities are linked on the same level of integration, namely the highest one possible, and equivalent to the concepts of "nature," "telos" or "beingness." Considering Seligman's results it can be concluded that stress in general and boredom in particular are best assessed by behavioral parameters, rather than by physiological ones. The idea that physiology is a form of behaviour as well (Wiepkema, personal communication 1982) obscures the presence of a qualitative difference between the two: behaviour has to do with the "whole" 
integrated animal, whereas physiology reflects the interaction of the various (unconscious) parts. Physiological factors cannot be weighed on the same scale as behavioural ones, though they can certainly be useful indicators.*

With the definition of stress given by Fraser, Ritchie and Fraser (1975), there is room for the considerations discussed above: "an abnormal or extreme adjustments in its behaviour or physiology, in order to cope with adverse aspects of its environment and management."

So far we have argued that homeostasis is not an adequate criterion for "normal," since it ignores the price an animal has to pay for its adaptation. It was also argued that behaviour as a parameter for stressful states is, qualitatively speaking, the most appropriate one. This shift in emphasis might make it easier to determine what is "normal" when we have to speak of "abnormal or extreme adjustments." "Extreme" and "abnormal" in a behavioural context do not refer to a numerical scale anymore as would be the case with physiological parameters, but to a qualitative change in behavioural adjustment. Redirected activity like tail-biting for example can then be regarded as an indicator of stress, since it is a form of abnormal behaviour.

Rather then speaking of understress, stress and overstress, abnormal adjustments could be indicated by using the terms "stress" and "distress;" distress being caused by understimulation, and stress by overstimulation. In this way "normal" refers to a certain level of "healthy" stimulation by specific stimuli (van Putten 1981), and not to a normal level of "stress." It is true that animals need a certain amount of stimulating "pressure" from the environment to develop their "fitness," their flexible response to changing conditions. But if the terms "understress" and "overstress" were used as Ewbank (1973) proposed, thereby accepting the "normality" of stress, or even calling it beneficial (Ewbank 1973), the adverse quality of the term "stress" would be very much diminished and thereby lose most of its meaning.

Boredom, in the framework developed above, can be characterized as a form of distress, resulting from chronic understimulation. Important criteria are the different forms of abnormal behaviour, mentioned in the previous paragraph. In physiology, hardly any relevant research about the effects of understimulation has been done; a few relevant experiments will be discussed shortly. It seems important to consider

\footnotetext{
*Psychological-cognitive and emotional factors can be more potent in producing physiological changes such as increased production of natural opiates than physical trauma per se (Miczek, K.A. et al. 1982. Science 215:1520-1522)-Ed.
} 
that the physiological reaction towards understimulation might be (fundamentally) different from the reaction to overstimulation, which is aimed at a homeostatic equilibrium.

\section{CONSEQUENCES FOR THE FIELD OF ANIMAL WELFARE}

In order to make it possible for the natural sciences to study animal well-being, an operational definition of "well-being" is necessary. The definition given by Lorz (1979) has been widely accepted as useful in this context: "welfare implies a state of harmony, both physical and psychological, of the animal with itself and with its environment. Health and normal behaviour are usually indicators for well-being. They presuppose a life-course which is species-specific, and which does justice to species-specific behaviour."

As can be seen from the previous paragraphs boredom represents a serious impairment of well-being as defined above since it implies a fundamental lack of behavioural possibilities for an animal. Yet in a larger context, so it is argued by many, this kind of suffering is only relative. In nature, animals experience all kinds of other, harmful and adverse conditions, such as bad weather, lack of food and the pressure of predators. These are eliminated in intensive farm systems, where the basic existence of an animal is guaranteed. How can we ever weigh these different elements on an overall scale of well-being?

The argument implies that an ideal situation is not possible, and therefore the present husbandry system might give an animal a different environment from its natural one, but not necessarily a worse one. However, this line of thought leaves out the fact that we as humans have consciously taken responsibility for the lives and wellbeing of our farm animals. Natural conditions for wild animals are beyond human responsibility, but it lies fully within our power to provide farm animals with whatever they need, "and there can be no justification for continuation of the conditions once severe strain has been diagnosed" (McBride 1979). Not providing animals with the opportunity to express their behavioural needs is therefore a conscious choice, dependent upon our own moral and economic standards. Only from a dualistic perspective can one compare natural and confinement conditions as if they were two "objective" situations. From an involved perspective, it is clear that however thoroughly we study needs and adaptive capacities of animals, in the end it remains a subjective choice whether we realize certain options for the animal or not; whether we force an animal to adapt, or give it room to express its basic behavioural drives. "Potentiality is an unseen reality," and as 
long as we know that we could give an animal more stimulation, we will have to find good reasons not to give it, however great the animal's adaptive capacities.

Another option we have in the conflict present in farms, laboratories and zoos between the animal's needs and its actual environment, is not to adjust the environment to the animal, but the animal to the environment. By altering its genetic make-up fundamentally through selection and genetic manipulation, we could "create" animals whose needs can be fulfilled in a man-made, economically oriented environment. By selecting animals "that are less aware of their environment and so less likely to be distressed by it" (Duncan 1973), general animal welfare could be "improved" according to several authors (Craig 1982; Fauré 1980; Beilharz 1982). Raymond (1980) rejects this idea, however, not on ethical grounds but for the practical reason that it takes a very long time; in the meantime our economic needs or ethical framework might change, and then it would be hard to reverse the process. Adjusting the environment to the animal is more efficient on a shortterm basis and more flexible. But apart from the practical objections, one can have serious ethical objections. Changing animals in this way is again one step further on the road of the manipulation of life and the acquisition of power over the world. I do not see this as a desirable direction, and I think we would harm ourselves as much as the animals by alienating ourselves in this way from natural life.

Boredom is a serious problem in present husbandry systems. In the next section evidence for this statement will be provided, and the importance of boredom in relation to other parameters of well-being will be discussed.

\section{PART II}

\section{BOREDOM IN AGRICULTURAL PRODUCTION SYSTEMS}

We have noted earlier that very little serious research about animal boredom has been performed. But work on closely related subjects such as housing systems and stereotypic behaviour is very relevant to our understanding of boredom.

In the field of farm animal welfare, most research on environmental deprivation seems to be concentrated on battery cage chickens and on sows and their litters kept in close confinement. Cows appear to have much less need for external stimulation. This may be due to their rumination process, which provides self-stimulation via chewing of the cud and grooming, and thus "boredom and aggression are reduced 
in establishing groups of cattle" (Albright 1982). Yet in veal calves boredom might be considered a serious problem. Because of isolation and lack of opportunity to fulfill their needs, calves lick and suck themselves, other calves, walls and inanimate objects. Health problems are often the result (Albright 1982).

A general description of present housing systems of pigs and chickens will now be given, and behavioural and physiological evidence of boredom in these systems presented. The effect that boredom has on other welfare criteria such as productivity, reproductivity, disease susceptibility, etc., will be discussed and a general evaluation of boredom as an indicator of welfare closes this section.

\section{HOUSING SYSTEMS}

The housing systems of chickens and sows have changed dramatically since the 1930's (Sainsbury 1978) and 1950's (van Putten 1982a). Our improved technological ability to develop a completely artificially controlled microclimate (Sainsbury 1978), the rapidly growing monopoly of the animal-feed industry (van Putten 1982a), the role of genetic science in the selection for productive animals, along with the increasing cost of land and labour, have worked together to press farmers to move the animals from outside yards to increasingly restricted environments, "where technical demands were given a higher priority than the animal's basic needs" (Ekesbo 1981a). As a result "commercial egglayers" are housed mostly in multibird cages with the birds kept in groups of 3 to 5 with considerable restriction of movements (Sainsbury 1978).

Sows are usually kept in individual pens and are tethered, preventing social contact with other sows. The floor is bare; oestrus is usually induced with hormones (because spontaneous oestrus disappears in the absence of social contact), and piglets are weaned at ever earlier ages (Lean 1978).

\section{BEHAVIOURAL EVIDENCE FOR BOREDOM IN PIGS AND CHICKENS}

\section{Sows and piglets}

"The type of pigs most affected by the extreme changes in housing systems are sows" (Buchenauer 1981). Tethering or restraint deprives them of their natural tendency to be active and inquisitive, and the lives of sows have become "extremely dull" (van Putten $1982 \mathrm{~b})$; their great need to explore the environment is reflected in their 
continuous use (given the opportunity) of their very sensitive noses (Hartsock, personal communication, 1982). In an article on sow health and housing Ekesbo (1981a) reports that tied sows are significantly less active during daytime than loose sows (respectively $32 \%$ versus 59\%). During this active time the loose sows carried out 12 different behaviour patterns with straw while for the tied sows, only two or three behaviour patterns involving straw were observed. Furthermore, Ekesbo (1981a) also notes that pig breeders have always given their animals separate areas for feeding, defecating and lying. Recent investigations have shown that loose sows divide their time in these three areas accompanied by 1216 social interactions, with 12 different patterns of behaviour. Tied sows only performed 236 interactions, while three patterns were completely absent.

Daelemans (1981) also argues that loose sows have a chance to move between separate areas for drinking and eating, thereby being able to gratify their apparently highly motivated need for exercise (Ekesbo 1981a). Baxter (1981) adds nest building to the list of behavioural needs. Restrained sows can be observed trying to break away before farrowing, because of their high motivation to move around and arrange a nesting area (van Putten 1982b; Buchenauer 1981; Vestergaard 1981).

Restrained sows demonstrate a high incidence of abnormal behaviour, which can be as much as $17.5 \%$ of the whole range of behaviour patterns (Buchenauer 1981). Stereotypical behaviour such as "weaving;" redirected activity such as "bar-biting," licking bars, trough floor and chain; "play-drinking," and vacuum behaviour such as "teethgrinding," "air-chewing," "tongue rolling" and rooting; and a general restlessness, are strong evidence of frustration due to lack of adequate stimuli (Ekesbo 1981a; Vestergaard 1981; Sambraus 1981; van Putten 1982b; Buchenauer 1981). Other indicators are the long periods, up to six hours, of "sitting," which has been attributed to significant drowsiness (Buchenauer 1981). Vestergaard (1981), Sambraus (1981) and Fraser (1968) report observations of sows sitting with their heads hanging down, or pressed against the stall divisions. Standing, which occurs for long periods, may be regarded as a conflict between the desire for activity and the impossibility to achieve it $\mathrm{Bu}-$ chenauer 1981).

The absence of straw also appears to be a significant deprivation. The effect of its presence or absence is discussed by many authors (Ekesbo 1981a; Vestergaard 1981; Sambraus 1981). Vestergaard (1981) reports in fact that oral and other stereotypies (such as weaving, vacuum-chewing, bar-biting) were reduced by loose straw. He found that such abnormal behaviour would increase within a few days after the removal of straw and decrease as soon as straw was present. This 
suggests that stereotypic behaviour might not be a remnant, left over from adaptation to some adverse situation in the past (Wiepkema 1982), but an immediate response to the adequacy of the environment. At the same time, straw could be used as nest building material (van Putten 1982b).

Piglets are never restrained, but the effect of the absence or presence of straw on their behaviour has been reported in several studies. When straw is present, rooting and chewing are more common, and other patterns such as nest building behaviour and play with the straw are elicited (Troxler 1980; van Putten and Dammers 1976). When straw is absent, redirected exploratory behaviour such as nibbling on other piglets and inanimate objects occurs (Troxler 1980; van Putten and Dammers 1976; Buchenauer 1981). Tail-biting is reported to be positively correlated with the absence of straw, since the provision of straw reduces this behaviour (Sambraus 1981; Buchenauer 1981; Koomans 1981). Therefore tail-biting might be a sign of boredom (Ewbank 1981; Bareham and Vestergaard 1981). In the straw barn, playing and fighting occur more than in cages (Bure 1981a), so straw in pig pens provides play material and reduces boredom (Bareham and Vestergaard 1981). "By enriching even a small environment, ...their reactivity towards unfamiliar stimuli drops dramatically, and approaches the low intensity and short duration seen under semi-natural condition" (Stolba and Wood-Gush 1980).

The long list of stereotypic and conflict behaviour, related to exploratory behaviour, feeding behaviour and locomotion in a richer environment where the sows are not restrained, provides evidence that boredom is a real problem for pigs in modern confinement systems without straw or some other substance to stimulate various natural behaviours.

\section{CHICKENS IN BATTERY CAGES}

The chicken is a very different animal and is also considered to be more primitive than a pig (Duncan 1981). Nevertheless, "deprivation of external stimuli is a factor to be considered even in an animal as phylogenetically primitive as a fowl" (Wood-Gush 1973).

Compared to deep litter pens, battery cages restrict behavioural patterns such as turning, dust-bathing, ground-pecking, wing-flapping, movement flapping and general locomotion (Bareham 1972, 1976; Duncan 1979; Hughes 1978). Furthermore, the absence of litter and nest boxes makes dust-bathing and nesting behaviour impossible.

As was observed for pigs above, the restriction of several behavioural possibilities is accompanied by a range of abnormal behaviour 
patterns, like stereotypic movements and redirected activities. The most prevalent abnormalities are feather-pecking, as a form of cannibalism, stereotypic pacing, stereotypic headflicking, displacement preening and vacuum dust-bathing.

"The most important factor contributing to feather-pecking is the absence of litter" (Duncan 1978). This is supported by experiments conducted by Bareham (1976). Hughes (1978) suggests that rather than being a result of boredom, feather-pecking is a substitute for ground-pecking. However, redirected activities are regarded as signs of boredom since they indicate the lack of stimuli. Feather-pecking can be compared to tail-biting in pigs: one animal, probably genetically disposed, starts the vice, and the others "learn" it from a few initiators (Duncan 1978; Sambraus 1981). Sambraus also states that, if chickens are fed on the ground instead of a trough, this reduces feather-pecking.

Stereotypic pacing is usually regarded as a sign of frustration due to the impossibility of performing nest building behaviour in a battery cage (Hughes 1978; Duncan 1978; Bareham 1976; Brantas 1980; Wood-Gush 1973; Fölsch 1980). Experimentally frustrated hens, in fact, do exhibit stereotypic pacing (Duncan 1978).

Head-flicking in laying hens described by Bareham (1972) can be compared to an equivalent sort of head turn in zoo animals when they are engaged in stereotypic pacing (Bareham 1972; Fox 1971). Its occurrence can be attributed to a monotonous environment with a restriction of external stimuli. This behaviour can be seen as the animal's attempt to increase its sensory input (Bareham 1972; Duncan 1981). Compensatory feeding behaviour, where chickens play with their food for long periods, without a higher intake of food, can be regarded as a compensation for other behaviour which has become impossible. A similar phenomenon occurs in pigs. Excessive preening can likewise be interpreted as a sign of "mild frustration" in the form of compensatory activity (Bareham 1976; Duncan 1979). The occurrence of vacuum dust-bathing indicates the innate need for a hen to perform this behaviour (Hughes 1980; Vestergaard 1981). The same is true of the need for wing-flapping and body/wing shaking, which may accumulate as well during deprivation (Vestergaard 1981).

Aggression might be considered as a sign of frustration due to deprivation, since it can be reduced by providing hens with a nest box (Vestergaard 1981). Vestergaard furthermore states that this indicates that "the birds really do miss those things."

From the evidence presented above, it can be concluded that boredom, as defined earlier, is a concept applicable to the chicken as well. The fact that they miss exploration-eliciting stimuli, and stimuli that 
facilitate other natural behaviour, can be inferred from the presence of many abnormal behaviour patterns, and from experiments that have shown that chickens prefer to work for their food rather than have it available freely (Wood-Gush 1973).

\section{PHYSIOLOGICAL INDICATORS OF BOREDOM}

Although it was suggested that stress, and distress due to understimulation, are detected mainly through behavioural phenomena, this does not mean that there are no physiological indicators. However, hardly any direct research into physiological responses to understimulation has yet been done. It is known from several experiments (Dantzer and Morméde 1981; Wiepkema 1982) that deprivation can originally lead to rise of plasma corticosteroid levels. But stereotypic behaviour such as chain-nibbling in pigs during food deprivation reduces the hormone levels considerably (Dantzer and Morméde 1981). As a result of these experiments it was concluded that circulating ACTH and corticosteroid levels are not sensitive to chronic stress (which boredom is considered to be). However, Barnett, Hemsworth, and Hand (1982/83) do refer to corticosteroid levels as parameters for chronic stress, based on experiments about the effect of handling pigs. Corticosteroids might be sensitive to chronic stress, therefore, but not to chronic distress. This is supported by the fact that none of the three studies done so far on understimulation in chickens indicates any difference between battery cages and deep litter pens in adrenal activity (Freeman 1978). One can speculate that there may be physiological indicators that correlate with understimulation, e.g. the neurotransmitter norepinephrine (Seligman 1975).

\section{THE EFFECT OF BOREDOM ON PHYSICAL CHARACTERISTICS OF AN ANIMAL}

\section{Production}

A bored pig is a slower growing pig, and "time is money" (Jesse, Wall Street Journal-11/1982). Jesse reported that a group of pigs, moved around to other, identical pens twice before slaughter, gained 1 pound more per pig per week than a control group. More stimulation, and a different view of the other pigs around them, are given as the explanation for this. Similar results were found by Koomans (1981): fattening pigs housed in an open front piggery with straw had a significantly higher average daily gain, and higher average back fat, than those without straw. The average food conversion was the same, which indicates that the animals ate more per day. This was also noted by 
Jesse who stated of his pigs that "they felt better and ate better." As tail-biting may result in condemnation to death at the abbatoir, straw given to prevent tail-biting can minimize production loss in an indirect way (Bareham and Vestergaard 1981).

In chicken farming both better and worse production have been observed in pens compared to cages (Bareham 1972). The occurrence of cannibalism and extreme flightiness does decrease egg production (Craig 1982), but how this correlates with housing in cages or pens is not clear. There are many different factors at work, and a definitive experiment has not yet been carried out.

Reproduction

The adverse effects of restraint on sows are indicated by a number of results. First, sows come into heat earlier in a free-range environment, the main reason being the social stimulation from other sows (van Putten 1982a), but also because piglets suckle less. The constant suckling in intensive systems retards oestrus (Stolba 1982). In an indirect way, restraint, and thereby the prevention of nesting behaviour, affects reproduction: the resulting stress can cause inflammation of udder and uterus, and lactation becomes impossible. This syndrome is especially prevalent in gilts. Also, indications have been found that restraint at farrowing increases the incidence of still births, mummified piglets and piglets with splaylegs (Baxter 1981; Ekesbo 1981a). Disease-susceptibility

An increase in the frequency of disease in sows correlates with the increased restraint of sows in confinement systems. It is not unusual that continuous medication is needed to prevent disease, and this is a poor way of maintaining the animal's health compared to changing the environment (Ekesbo 1981a; Buchenauer 1981). Concerning the direct correlation between exploratory behaviour and disease, different studies have shown that there is a significantly higher incidence of Salmonella (diarrhea) infection in herds with no straw (Metz and Oosterlee 1980; Ekesbo 1981b), although rationally the opposite might be expected because straw may be seen as a good medium for building up an infection fast (Truyen 1981). Backström's studies of environmental factors showed that general health was better in pens with straw compared to other beddings, and much better than in pens with no bedding (Ekesbo 1981a).

In this same line Metz and Oosterlee (1980) found a lower antibody level and therefore a greater disease susceptibility, of tethered sows in pens without straw, compared with free sows in pens with straw. Total morbidity, and also the occurrence of the mastitis syndrome (agalactia toxemia) was shown to be much higher for tethered sows; the litters of tethered sows in a small pen had a higher total morbidity than litters of free sows in large pens (Ekesbo 1981a). 
For sows and piglets it seems there is a direct correlation between disease susceptibility and restraint and the absence of straw, which are considered to be the two conditions which are very likely to cause boredom. Besides diarrhea and mastitis, infectious pneumonia is a frequently occurring and highly damaging illness in pig operations.

For fowl, experimental work has been done on the effect of stress on disease susceptibility (Freeman 1976; Siegel 1980). How these results apply to the different aspects of battery cage life is not clear; only the effects of social stress as a result of reduced space have been examined (Siegel 1980) and were found to cause decreased antibody levels and greater susceptibility to viral diseases such as New Castle disease, Marek's disease, hemorrhagic enteritis, and Salmonella infection. (However, resistance to bacterial infection seemed to be increased.) Most of these stress factors are coupled with a rise in corticosteroid levels (Freeman 1976), but Freeman also reports that antibody production can be shown "to be impaired by stressors which do not even evoke a rise in plasma corticosterone. If more research would be done in this field, it might be speculated that lack of stimulation, and resulting boredom and frustration, can be forms of non-corticosteroid mediated chronic stress that affect antibody production."

\section{PHYSICAL INJURY}

The most obvious examples of physical injury as a result of boredom are the vices of tail-biting in pigs and feather-pecking in laying hens. These are countered by debeaking hens and cutting the tails of newly born piglets. From a welfare point this is unacceptable, certainly for the hen, since the beak is a primary sensory tool for receiving information from the environment (Duncan 1978). Many physical injuries are not directly a result of boredom like the examples above, but are a result of the same barren environment that causes the boredom. For instance, wounds on feet and back in pigs are a result of the bare, hard floors (Troxler 1980; Baxter 1981); just as severely damaged claws of hens are caused by the wire floors of battery cages (Tauson 1980). These injuries could be prevented by providing some sort of bedding; this would, at the same time, lead to the alleviation of boredom. The same is true for the tethering of sows; the many traumatic injuries attributed to tethering (Ekesbo 1981a) could be prevented by housing the sows in a free-range pen. The close correlation between understimulation and injury, due to the same practice, indicates the general inadequacy and undesirability of that practice. 


\section{GENERAL EVALUATION}

Studies described in this chapter about the influence of straw for pigs and deep litter for laying hens confirm the idea that environmental enrichment will be beneficial and adequate as a remedy against some forms of abnormal behaviour.

Is it important to consider boredom seriously as a criterion of welfare, and what its impact is compared to other welfare criteria?

An essential characteristic of boredom in evaluating welfare is that it directly refers to the mental state of the animal and therefore directly implies suffering. Productivity and reproduction are indirect parameters; they are not only animal centered, since the farmer's well-being depends on good productivity as well. Physical injury and disease are animal centered, and it is generally accepted that these are adverse to the animals' mental well-being. If not too severe, and not too prolonged, however, pain and disease might be "bearable." The same may be the case with many forms of stress as a result of overstimulation, since they are temporary and do not fundamentally impair the integrity of the whole animal. But boredom as it is present in today's production system causes the animals to suffer on their most existential level. An animal which cannot express its specific behaviour patterns loses its fundamental selfhood, cannot develop itself in relation to its environment and cannot bear anything, pain in particular. Deprivation of selfhood is the most fundamental affliction that can be imposed upon an individual, be it pig, chicken or human.

In nature, animals are never bored. A certain amount of environmental and social stress might be present, but that does not deprive the animal of its capacity to deal with it. If not too severe, it might even enhance its coping abilities. Weather conditions and social interaction are factors that might be desirable in husbandry systems as well. In human society, prisons are confinement systems where material care is sufficient, but the freedom of self-expression is intentionally restricted. This may be a moral choice, but we certainly do not consider a prison a normal environment, and boredom is known to be a chronic problem there.

To suggest that boredom might be fundamentally worse than several forms of pain does not imply, of course, that the infliction of pain should not be avoided where possible. It is not a matter of either one or the other. Rather, as has been discussed in this paper, it is very likely that many other welfare characteristics will be improved as well by alleviating boredom. Production, reproduction, and health can be directly improved, because there is either a direct causal relationship between boredom and these characteristics, or there is a positive cor- 
relation, as between boredom and physical injury, both being the result of the same causal factor.

The fact that boredom does have quite a wide range of effects on other aspects of the individual animal, shows that it is not just anthropomorphic to state that boredom is fundamentally harmful to the integrity of an animal. Its complete physical health is affected and the deprivation of selfhood is one of the most serious attacks on mental health. This is not an anthropomorphic statement, but a statement about the quality of life, and therefore applying to all living beings.

\section{CONCLUSIONS}

1. An empathetic, caring relationship between observer and animal is fundamental if we are aiming at knowledge of the subjective experience of the animal under certain conditions. This can be a "personal" relationship between the observer and an individual animal, but it can also take the form of a general empathetic attitude towards a group of animals, or towards lower, less individuated animals.

A detached, dualistic relationship can be regarded as resulting from an interest in knowledge for the sake of manipulation; an attitude of (nonpossessive) love on the other hand has the intention of knowing an object in order to be able to facilitate that the object can truly be or become itself. Therefore, an empathetic attitude may be more "objective" than a detached one (see also Section II, Empathy, Humaneness and Animal Welfare). Furthermore, the alienation between knower and known is replaced by involvement, and quality becomes more important than quantity because an attitude of care regards an animal as a qualitative being instead of a quantifiable mechanism.

2. Each animal exists on its own level of beingness, implying that awareness and emotional experience are fundamental characteristics of life, existing down to the lowest levels. However far removed from human inner experience as the lower levels might be, the concept of beingness implies a respect for the selfhood of each species, and a recognition of the fact that the quality of life matters to each animal.

Many higher vertebrates, such as dogs, dolphins, elephants, primates, etc., show capacities which indicate self-awareness and a welldeveloped individual emotional life. They are intelligent and sensitive and an adequate environment is crucial for the proper expression of their selfhood. We should therefore be prepared to meet animals on their own terms in order to value their innate abilities and potentialities, instead of forcing them to "adapt" to man-made environments and to those conditions that cause them otherwise avoidable stress and distress. 
3. Behaviour is the qualitative expression of an animal's selfhood, and is therefore an end in itself, and not a means towards a homeostatic state, or towards successful reproduction. Each animal has basic, genetically inherited, behavioural needs which clearly matter to it, because when it is prevented from performing these behaviours it resorts to abnormal behaviour or becomes apathetic. An animal can be said to be bored when it has to adapt to its environment in an abnormal way, indicative of understimulation, in order to maintain its sense of selfhood. Boredom can be regarded as a form of distress, indicating that an animal is stressed, not due to overstimulation, but due to understimulation.

Behavioural criteria of boredom have been delineated in this paper and it was concluded that behaviour represents a higher level of integration than physiology; it concerns the whole, integrated animal, whereas physiology reflects the interaction of the various (unconscious) parts. Physiological processes are directed at the maintenance of a homeostatic state. This state, however, is not necessarily equivalent to a state of well-being. Boredom is a form of suffering which primarily is the result of a cognitive process, directly linked to the behavioural possibilities an animal has. Physiological observations are not more objective because they are easier to quantify; in contrast with behaviour they miss the direct link to the subjective experience of an animal, and are therefore, secondary though they might be, useful indicators.

4. Many forms of abnormal behaviour in pigs and chickens are described. Their relatedness to boredom appears from the fact that they usually disappear when some form of environmental enrichment takes place, and when the animals are more able to express different behaviours.

For sows and piglets, the fulfillment of basic needs which prevent the worst forms of boredom seem to be: the ability to move unrestrictedly in a certain amount of space; the provision of straw and contact with other conspecifics.

For chickens, these needs are: some space to move, material to perform basic nest building behaviour and the opportunity to search for food on the floor.

In a housing system where food and drink are provided, the most important remedy against boredom is the provision of explorative possibilities. Doing something, whether it be playing, looking for food, or building a nest, constitutes the basis for selfhood. Deprivation of selfhood is the most fundamental affliction for any living being, and is reflected in lower production, lower reproduction, higher disease susceptibility and an increasing amount of physical injury.

Recent research projects indicate that it is possible indeed to 
create environments for domestic animals which give them much more freedom to express their behavioural needs, within economic limits (Wood-Gush and Stolba 1982; Albright 1982). The argument that if an animal is productive it surely is healthy and adapted, obscures the fact that the use of medical drugs is essential to keep farm animals alive and productive (Fox 1983a). Medical care is very expensive, and the cart is constantly put before the horse in this way. Instead of starting to care for animals when it is almost too late, it seems better to accept care as the foundation for our attitude towards them.

In this paper I wanted to indicate and elaborate on the idea that there is an important and direct link between a meta-scientific starting point of empathetic relationship, and practical guidelines for animal husbandry. The willingness to meet animals in a relationship of friendship, thereby discovering their inner world, can result in useful, animal-centered knowledge of their needs and preferences. We might in this way be able to create an environment for the animal which is healthy, both physically and mentally, and which will benefit not only them, but ourselves as well. 


\section{REFERENCES}

Albright, J.L. 1982. Production changes improve cow veal welfare. Feedstuffs April 12:23-33.

American Society of Agricultural Engineers. 1981. Engineering perspectives on farm animal care. Paper no. 81-4580.

Assem, J. van den 1973. Gedrag als aanpassingsfenomeen, een beschouwing over de functie van gedra. In: Ethologie, de biologie van gedrag. Pudco, Wageningen. pp. 17-39.

Baldwin, B.A. and Stephens, D.B. 1971. The effects of conditioned behaviour and environmental factors on plasma corticosteroid levels in pigs. Physiology and Behaviour. 10:267-74.

Bareham, J.R. 1972. Effects of cages and semi-intensive deep litter pens on the behaviour, adrenal response and production in two strains of laying hens. Br.Vet.J. 128:153-63.

Bareham, J.R. 1976. A comparison of the behaviour and production of laying hens in experimental and conventional battery cages. Applied Animal Ethology 2:291303.

Bareham, J.R. and Vestergaard, K. 1981. Welfare and productivity. In: Research and development in relation to farm animal welfare. Basel: Birkhäuser Verlag.

Barnett, J.L., Hemsworth, P.H. and Hand, A.M. 1982/83. Effects of chronic stress on some blood parameters in the pig. Applied Animal Ethology 9:273-7.

Baxter, S.H. 1981. Welfare and the housing of the sow and suckling pigs. In: Sybesma, W., ed. The welfare of pigs. The Hague: Martinus Nijhoff.

Baxter, M.R. 1982/83. Ethology in environmental design for animal production. Applied Animal Ethology 9:207-20.

Beilharz, R.G. 1982. Genetic adaptation in relation to animal welfare. Int.J.Stud.Anim. Prob. 3(2):117-24.

Beuving, G. 1980. Corticosteroids in laying hens. In: Moss, R., ed. The laying hen and its environment. The Hague: Martinus Nijhoff.

Bessei, W. 1980. In: Moss, R., ed. The laying hen and its environment. The Hague: Martinus Nijhoff.

Boice, R. 1981. Captivity and feralization. Psychological Bulletin 89(3):407-21.

Brantas, G.C. 1975. Welzijn, productie en profijt. Tijdschr. Diergeneesk. deel 100(13): 703-8.

Brantas, G.C. 1980. The pre-laying behaviour of laying hens in cages with and without laying nests. In: Moss, R., ed. The laying hen and its environment. The Hague: Martinus Nijhoff.

Buchenauer, D. 1981. Parameters for assessing welfare, ethological criteria. In: Sybesma, W., ed. The welfare of pigs. The Hague: Martinus Nijhoff.

Bure', R.G. 1981a. Animal well-being and housing systems for piglets. In: Sybesma, W., ed. The welfare of pigs. The Hague: Martinus Nijhoff.

Buré, R.G. 1981b. In: Sybesma, W., ed. The welfare of pigs. The Hague: Martinus Nijhoff. General discussion, p. 136.

Cassel, E.J. 1982. The nature of suffering and the goals of medicine. N.Engl.J.Med. 306:639-45.

Cave, G.P. 1982. Animals, Heidegger and the right to live. Environmental Ethics4(3): 249-54.

Craig, J.V. 1982. Behavioral and genetic adaptation of laying hens to high density environments. Bioscience 32(1):33-7.

Daelemans, J. 1981. The impact of the farrowing pen on the sow and her piglets. In: Sybesma, W., ed. The welfare of pigs. The Hague: Martinus Nijhoff. 
Dantzer, R. 1981. In: Sybesma, W., ed. The welfare of pigs. The Hague: Martinus Nijhoff. General discussion, p. 133.

Dantzer, R. and Morméde, P. 1979. Le stress en elevage intensif. Actualités scientifiques et agronomiques no. 3. Masson, Paris.

Dantzer, R. and Morméde, P. 1981. Can physiological criteria be used to assess welfare in pigs? In: Sybesma, W., ed. The welfare of pigs. The Hague: Martinus Nijhoff.

Daschbach, N.J., Schein, M.W. and Haines, D.E. 1982/83. Cage-size effect on locomotor, grooming and agonistic behaviours of the slow loris, Nycticebus coucang (primates, Lorisidae). Applied Animal Ethology 9:317-30.

Dawkins, M.S. 1980. Animal suffering: The science of animal welfare. London, New York: Chapman and Hall.

Debrock, G. 1982. Wisenschaft als Ethik. Manuscript of lecture at Bocholt (Germany). Duncan, I.J.H. 1973. Can the psychologist measure stress? The New Scientist 18 Oct:173-5.

Duncan, I.J.H. 1978. Overall assessment of poultry welfare. In: Proceedings First Danish Seminar on Poultry Welfare in Egglaying Cages. pp. 79-87.

Duncan, I.J.H. 1979. Can scientific research help in assessment of animal welfare? In: Proceedings of a symposium held at the University of New England, Armidale, Australia. pp. 169-74.

Duncan, I.J.H. 1981. Animal behaviour and welfare. In: Clark, J.A., ed. Environmental aspects of housing for animal production. London: Butterworths.

Ekesbo, I. 1981a. Some aspects of sow health and housing. In: Sybesma, W., ed. The welfare of pigs. The Hague: Martinus Nijhoff.

Ekesbo, I. 1981b. In: Sybesma, W., ed. The welfare of pigs. The Hague: Martinus Nijhoff. General discussion, p. 233.

Ewbank, R. 1973. Use and abuse of the term "Stress" in husbandry and welfare. Vet.Rec. June 30:709-10.

Ewbank, R. 1981. In: Wood-Gush, D.G.M., Dawkins, M., Ewbank, R., eds. Self-awareness in domesticated animals. Hertfordshire: UFAW. General discussion, p. 50.

Fauré, J.M. 1980. To adapt the environment to the bird, or the bird to the environment? In: Moss, R., ed. The laying hen and its environment. The Hague: Martinus Nijhoff Publishers.

Fölsch, D.W. 1980. Essential behavioural needs. In: Moss, R., ed. The laying hen and its environment. The Hague: Martinus Nijhoff.

Fox, M.W. 1971. Psychopathology in man and lower animals. J.A.V.M.A. 159(1):66-77.

Fox, M.W. 1974. Concepts in ethology. Minneapolis: University of Minnesota Press.

Fox, M.W. 1982. Are most animals "mindless automatons?": A reply to Gordon G. Gallup, Jr. American J. Primatol 3:341-3.

Fox, M.W. 1983a. Farm animals: husbandry, behavior, and veterinary care: Viewpoints of a critic. Baltimore: University Park Press.

Fox, M.W. 1983b. Scientific objectivity and the subjective world. In: Rowan, A., ed. Animal awareness-human perceptions: Implications for animal welfare. Albany, New York: In press.

Fraser, A.F. 1968. Behaviour disorders in domestic animals. In: Fox, M.W., ed. Abnor mal behaviour in animals. Philadelphia, London: W.B. Saunders Co.

Fraser, A.F. 1980. Ethology, welfare and preventive medicine for livestock. Applied Animal Ethology 6:103-9.

Fraser, D., Ritchie, J.S.D. and Fraser, A.F. 1975. The term stress in a veterinary context. Br.Vet.J. 131:653-61.

Freeman, B.M. 1975. Physiological basis of stress. In: Proceedings of the Royal Society of Medicine 68:427-9.

Freeman, B.M. 1976. Stress and domestic fowl. A physiological reappraisal. World Poultry Science Journal 32(3):249-57. 
Freeman, B.M. 1978. Stress in caged layers. In: The First Danish Seminar on Poultry Welfare in Egglaying Cages. pp. 57-61.

Friend, T.H. 1980. Stress: What is it, and how can it be quantified? Int.J.Stud.Anim. Prob. 1(6):366-74.

Gilson, E. 1976. Descartes: Discours de la méthode; texte et commentaire. 5me edition. Librairie Philosophique. J.Vrin. Paris.

Griffin, D.R. 1977. Whitehead's philosophy and some general notions of physics and biology. In: Cobb, J.B. and Griffin, D.R., eds., Mind in nature. Washington, D.C.: University Press of America.

Griffin, D.R. 1981a. The question of animal awareness. 2nd ed. New York: Rockefeller University Press.

Griffin, D.R. 1981b. The problem of distinguishing awareness from responsiveness. In: Wood-Gush, D.G.M., Dawkins, M. and Ewbank, R., eds. Self-awareness in domesticated animals. Hertfordshire: UFAW.

Hammer, W., 1980. Einfluss von Tierbetreuer und Haltungsverfahren auf die Gewichtsentwicklung von Ferkeln. In: KTBL-Schrift 264. Aktuelle Arbeiten zur artgemässen Tierhaltung. Darmstadt-Kranichstein.

Hughes, B.O. 1978. Behaviour in different environments and its implications for welfare. In: The First Danish Seminar on Poultry Welfare in Egglaying Cages. pp. 21-27.

Hughes, B.O. 1980. The assessment of behavioural needs. In: Sybesma, V., ed. The laying hen and its environment. The Hague: Martinus Nijhoff.

Humphrey, N. 1981. In: Wood-Gush, D.G.M., Dawkins, M. and Ewbank, R., eds. Self-awareness in domesticated animals. Hertfordshire: UFAW. General discussion, pp. 10, 50.

Ingram, D.L. 1981. In: Sybesma, W., ed. The welfare of pigs. The Hague: Martinus Nijhoff.

Kiley-Worthington, M. 1981. In: Wood-Gush, D.G.M., Dawkins, M., Ewbank, R., eds. Self-awareness in domesticated animals. Hertfordshire: UFAW. General discussion, p. 50.

Koomans, P. 1981. Open front piggeries with and without straw. In: Sybesma, W., eds. The welfare of pigs. The Hague: Martinus Nijhoff.

Lean, I.J. 1978. The pig industry. In: The welfare of food-animals. Hertfordshire: UFAW.

Lorz, A. 1979. Tierschutzgesetz. Kommentar. Verl. C.H. Beck, München.

Manning. A. 1972. An introduction to animal behaviour. 2nd. ed. London: Edward Arnold Ltd.

Markowitz, H. 1982. Behavioural enrichment in the zoo. New York, London: Van Nostrand Reinhold Co.

McBride, G. 1979. Adaptation and welfare at the man-animal interface. Proceedings of a symposium held at the University of New England, Armidale NSW Australia pp. 195-9.

Meijer-Holzapfel, M. 1968. Abnormal behaviour in zoo-animals. In: Fox, M.W., ed. $A b$ normal behaviour in animals. Philadelphia, London: W.B. Saunders Co.

Metz, J.H.M. and Oosterlee, C.C. 1980. Immunologische und ethologische Kriterien für artgemässe Haltung von Sauen und Ferkeln. In: KTBL-schrift 264. Aktuelle Arbeiten zure artegemässen Tierhaltung, Darmstadt-Kranichstein.

Moss, B.W. 1981a. The development of a blood profile for stress assessment. In: Sybesma, W., ed. The welfare of pigs. The Hague: Martinus Nijhoff.

Moss, B.W. 1981b. In: Sybesma, W., ed. The welfare of pigs. The Hague: Martinus Nijhoff. General discussion, p. 137.

Murphy, L.B. 1978. A review of animal welfare and intensive animal production. Report of the Poultry Section, Queensland Department of Primary Industries, Australia. 
Perry, G. 1973. Can the physiologist measure stress? The New Scientist 60:175-7.

Putten, G. van. 1981. Het meten van welzijn bij landbouwhuisdieren Tijdschr. Diergeneesk 106(3):106-18.

Putten, G. van. 1982a. De zeugenhouderij. In: Studiecommisie intensieve veehouderij; fokzeugen, achtste rapport, hoofdstuk 2. Ned.Ver.tot Besch.v.Dieren, Den Haag.

Putten, G. van. 1982b. Welzijnsaspecten. In: Studiecommissie intensieve veehouderij: fokzeugen, achtse rapport, hoofstuk 4. De Haag: Ned. Ver. tot Besch. v. Dieren.

Putten, G. van, and Dammers, J. 1976. A comparative study of the well-being of piglets reared conventionally and in cages. Applied Animal Ethology 2:339-56.

Raymond, W.F. 1980. In: Moss, R., ed. The laying hen and its environment. The Hague: Martinus Nijhoff. Summary, p. 323.

Sainsbury, M.A. 1978. The poultry industry. In: The welfare of food animals. Proceedings of a symposium by UFAW, Hertfordshire, pp. 51-59.

Sambraus, H.H. 1981. Beurteilung von Verhaltens-anomalien aus ethologisher Sicht. 2 GFT-Seminar für angewandte Nutztierethologie Bayerische Landesanstalt für Tierzucht. Grub: 1-9.

Sambraus, H.H. 1982. Ethologische Grundlage einer Tiergerechten Nutztierhaltung. In: Ethologische Aussagen zure artgerechten Nutzierhaltung. Birkhauser Verlag, Basel. pp. 22-41.

Seligman, M.E.P. 1975. Helplessness. San Francisco: W.H. Freeman and Co.

Siegel, H.S. 1980. Physiological stress in birds. Bioscience 30:529-34.

Stolba, A. and Wood-Gush, D.G.M. 1980. Arousal and exploration in growing pigs in different evironments. Applied Animal Ethology 6(4):382-3.

Stolba, A. 1982. Wild pigs point the way. Animal Welfare Institute Quarterly. 31(1):7.

Tauson, R. 1980. Cages: how could they be improved? In: Moss, R., ed. The laying hen and its environment. The Hague: Martinus Nijhoff.

Tranøy, K.E. 1977. Three thoughts about objectivity as a methodological norm. In: Danish Yearbook of Philosophy, Vol.14. Munksgaard, Copenhagen.

Troxler, J. 1980. Beurteilung zweier Haltungssysteme für Absatzferkel. In: $K T B L-$ schrift 264, Aktuelle Arbeiten zur artgemässen Tierhaltung, Darmstadt-Kranichstein.

Truyen, W.T. 1981. In: Sybesma, W., ed. The Welfare of Pigs. The Hague: Martinus Nijhoff. General discussion, pp. 232-3.

Verhoog, H. 1983. De relatie tussen biologie en menswetenschappen. Manuscript.

Vestergaard, K. 1981. Influence of fixation on the behaviour of sows. In: Sybesma, W., ed. The welfare of pigs. The Hague: Martinus Nijhoff.

Wemelsfelder, F. 1982. Gedrag als mogelijke indicator voor pijn bij biggen. Verslag van onderzoeksstage 109, IVO-Zeist. Niet voor publicatie.

Wiepkema, P.R. 1980. Ein biologische modell von Verhaltenssystemen. In: $K T B L-$ schrift 264, Aktuelle Arbeiten zur artgemässen Tierhaltung, Darmstadt-Kranichstein.

Wiepkema, P.R. 1982. On the identity and significance of disturbed behaviour in verterbrates. In: Bessei, W., ed. Disturbed behaviour in farm animals. Hohenheimer Arbeiten, Heft 121: Eugen Ulmer Verlag, Stuttgart.

Wood-Gush, D.G.M. 1973. Animal welfare in modern agriculture, Br.Vet.J. 129:16474.

Wood-Gush, D.G.M. 1981. In: Wood-Gush, D.G.M., Dawkins, M., Ewbank, R. eds. Self-awareness in domesticated animals. Hertfordshire: UFAW. General discussion.

Wood-Gush, D.G.M. and Stolba, A. 1982. Behaviour of pigs and the design of a new housing system. Applied Animal Ethology 8(6):583-4.

Zuriff, G. 1982. A dog remembers. The Sciences. Dec.:10-11. New York: The New York Academy of Sciences. 